\title{
Fibres as shear reinforcement in RC beams: an overview on assessment of material properties and design approaches
}

\author{
Joaquim A.O. Barros ${ }^{1}$, Stephen J. Foster ${ }^{2}$ \\ 1: Full Prof., ISISE, University of Minho, Guimarães, Portugal. \\ 2: Professor and Head, School of Civil and Environmental Engineering, UNSW Sydney.
}

\begin{abstract}
It is recognized that understanding at a material level is needed in the development of rational, physical-mechanical, models for predicting the behaviour of fibre reinforced concrete at service and strength limit conditions. To this end, understanding the post-cracking mechanisms of the fibres, and their symbiotic relationship with the cementitious matrix that surrounds them, is required for the development of realistic modelling approaches that accurately represent empirical observations. Several experimental test setups and inverse analysis procedures have been proposed to derive the fundamental stress-crack width $(\sigma-w)$ law, but a consensus still does not exists on the best strategy for its determination. In structures governed by shear, fibre reinforcement increases the stiffness and shear stress transfer across a crack, but a methodology to capture the contribution of fibres in this regards is challenging. To overcome this, a clear strategy is needed in deriving relationships that simulate fibre reinforcement mechanisms in the mobilized fracture modes and, also, develop design approaches capable of capturing the relevant contributions of the fibres. This study firstly reviews current inverse analysis models used to describe the tensile (Model I fracture) relationship for FRC and, secondly, discusses a newly proposed model, referred to as the integrated shear model (ISM). The ISM is developed from mesoscale observations from gamma- and X-ray imaging on FRC elements under Modes I and II fracture conditions. The resulting model is compared to test data reported in the literature and a good correlation is observed.
\end{abstract}

\section{Keywords}

Shear capacity, Mode I fracture parameters, Inverse analysis, Analytical models. 


\section{Introduction}

One of the most promising applications of fibre reinforcement for concrete structures is in one-way and punching shear. It is recognized that the post-cracking tensile capacity provided by fibre reinforcement in cement based materials (represented by the post-cracking stress versus crack opening relationship, $\sigma-w)$ is the most relevant in terms of describing the behaviour at serviceability and strength limit states, as well as for durability and other design limit conditions. Several experimental test setups and inverse analysis procedures have been proposed to define the $\sigma-w$ relationship; however, a consensus still does not exist on the best strategy for determining it. As current design models concentrate solely on specifying the post-cracking direct tensile strength, defined as Mode I fracture, inverse analysis procedures for the determination of the tensile response dominate the literature.

A methodology to capture the contribution of fibre reinforcement is challenging and the lack of a good physical understanding may contribute to the reasons why fibre reinforcement is not being routinely specified by designers, despite the high potential evidenced by the available research. To overcome this, a clear strategy is needed in deriving the fundamental relationships that simulate fibre reinforcement mechanisms in the mobilized fracture modes and, also, development of design approaches capable of capturing all relevant contributions of fibre reinforcement. As outlined above, current design model approaches concentrate on Mode I fracture in their determination of ultimate limit state conditions; however, slip along a crack dictates that Mode II mechanisms are relevant.

In this paper the concept of a physical-mechanical model, referred to as the integrated shear model (ISM), is described for determining the shear strength of beams where Mode II fracture is considered. The results are compared to fib Model Code 2010 (MC2010) model results for determining one-way shear capacity of beams.

\section{Strategies for evaluating the post-cracking tensile capacity for design at the strength limit state}

\subsection{Experimentally-based approaches}

\subsubsection{Three-point notched prims bending test (3PNBT)}

According to MC2010, the stress-crack width relationship to be used for simulating the post-cracking tensile capacity of FRC is determined from the residual flexural strength parameters, $f_{R j}$, obtained by performing three point notched prism bending tests (3PNBT), where a force versus crack mouth opening displacement (CMOD) is registered. Based on force values obtained in this tests, $F_{j}(j=1,2,3,4)$, the residual flexural strength is determined from:

$$
f_{R j}=\frac{3 \cdot F_{j} \cdot l}{2 \cdot b \cdot h_{s p}^{2}}
$$

where $l$ is the span length of the test beam, $b$ is the width of the specimen's cross section and $h_{s p}$ is the distance between the notch tip and the beam top surface. For an ultimate limit state 
(ULS) analysis, one of two models may be used: the rigid-plastic model of constant value of $f_{\text {Ftu }}$ up to $w_{u}$; and the (ii) linear model defined by the following two pair of values: $w=0$, $\sigma=f_{F t s} ; w=w_{u}, \sigma=f_{F t u}$, where $w_{u}$ is the ultimate crack opening corresponding to the ULS criterion (for shear it is recommended that $w_{u}=1.5 \mathrm{~mm}$ ). For the rigid-plastic model, the ultimate residual tensile strength is determined from:

$$
f_{\text {Ftu }}=\frac{f_{R 3}}{3}
$$

For the linear model, the serviceability and ultimate residual tensile strengths are obtained from:

$$
\begin{gathered}
f_{F t s}=0.45 \cdot f_{R 1} \\
f_{F t u}=f_{F t s}-\frac{w_{u}}{C M O D_{3}(=2.5 \mathrm{~mm})} \cdot\left(f_{F t s}-0.5 \cdot f_{R 3}+0.2 \cdot f_{R 1}\right) \geq 0
\end{gathered}
$$

According to several authors this methodology to derive the $\sigma-w$ relationship for a FRC (Salehian and Barros 2017, Lameiras et al. 2015, Amin et al. 2015) leads to unsafe predictions when compared to the results determined in direct tensile test (DTT). By cutting a notch in the specimen, the crack propagation is promoted through a section that may not be the one if this notch was not there. For the case where the notched plane is not aligned with the weakest one, for instance being crossed by a higher number of fibres (or more effectively arranged in terms of distribution and orientation) than of other weakest planes, the rotation process associated to the fracture propagation in a 3PNBT can promote the favourable snubbing fibre reinforcement mechanism (Lee and Foster 2007, Voo and Foster 2009), which contributes for the overestimation of the fracture performance of a FRC when evaluated from this test.

\subsubsection{Direct tensile test (DTT)}

A direct tensile test is recognized as being more capable of determining directly the fracture mode I parameters of a cement based material, but the relatively large time required to do the test and the high cost of equipment limit its use to the research domain. Apart from these concerns, the evaluation of the fracture parameters in strain softening FRC is performed in specimens where a notch is executed in an attempt of forcing just one surface where the fracture energy is consumed. The drawbacks pointed out to the 3PNBT are, therefore, also applicable to the DTT, although the detrimental effect of the curvature in the 3PNBT is not so significant in DTT.

In an attempt to escape the detrimental effect of notches, some authors use dog-bone type specimen, since this configuration has a high probability of capturing the weakest fracture zone, despite the smallest width in the central transversal section of the specimen that favours the propagation of the fracture through this plane. To avoid this weakness, a dog-bone type configuration with a constant cross section in the central part of the specimen has also been used (Susetyo 2009, Deluce and Vecchio 2013, Pereira et al. 2012, Carnovale and Vecchio 2014), but fracture in the transition zone at the extremities and the central part of the specimen can occur. This specimen configuration is the most used to characterize the tensile behaviour of strain hardening FRC (Pereira et al. 2012), where several cracks are expected to occur in 
the central part of the specimen, and a strain concept can be used due to the smeared nature of the cracking process, in-place of crack opening.

For determining the influence of fibre distribution and orientation some authors evaluate the fracture parameters in specimens extracted from relatively large elements, with cast conditions and volumetric parameters being as representative as possible of that in the real structure (Lameiras et al. 2015, Abrishambaf et al. 2013, Abrishambaf et al. 2016).

\subsubsection{Double edge wedge splitting test (DEWST)}

The double edge wedge splitting test (DEWST) was proposed by di Prisco et al. (2013) for the evaluation of the Mode I fracture properties of FRC. A pair of triangular grooves with a right angle, designated by "V-notch", is introduced transversally on the upper and lower faces of the specimen in its contact zones with the loading and supporting systems. The compressive force $(P)$ is applied through two steel bars laid into the $\mathrm{V}$-notches. The transverse tensile stress along the fracture surface is obtained from:

$$
\sigma_{c t}=\frac{\eta P}{h_{f s} \cdot l_{f s}}
$$

where $\eta$ is a reduction factor that depends on the concrete-to-steel bar frictional coefficient (di Prisco et al. 2013), $h_{f_{s}}(=120 \mathrm{~mm})$ and $l_{f_{s}}(=150 \mathrm{~mm})$ are the height and width of the fracture surface, respectively.

\subsubsection{Modified splitting tensile test (MSTT)}

The prismatic geometric configuration of the DEWST is not the most appropriate for extracting specimens from bulk FRC when the effect of fibre distribution and orientation on the post-cracking tensile capacity of FRC is intended to be assessed. To address this, the modified splitting tensile test (MSTT) was proposed by Lameiras et al. (2015). The MSTT specimen has a circumferential geometric configuration and can be easily extracted directly from to the bulk FRC in case of relatively thin elements (Lameiras et al. 2015, Abrishambaf et al. 2016), or can be obtained by slicing cylinder cores extracted from relatively thick elements (Alves et al. 2012, Barros et al. 2015). Besides the difference on the geometric configuration of the specimen, in the MSTT is introduced a pair of notches (one in each face of the specimen) in the loading plane in order to avoid the formation of cracks other than the one coinciding with the notched plane. However, the already reported detrimental effects in consequence of promoting the localization of the fracture surface are also applicable to the MSTT.

\subsubsection{Round panel test (RPT)}

The round panel test (RPT) described in ASTM C-1550 has a diameter $\left(d_{R P}\right)$ of $800 \mathrm{~mm}$, a thickness $\left(h_{R P}\right)$ of $75 \mathrm{~mm}$ and a radius to the supports $\left(S_{R P}\right)$ of $375 \mathrm{~mm}$. Since normally three cracks are formed in the panel test, at an approximate relative angle of 120 degrees between them, fibres of almost all possible orientations bridge the cracks. Thus, the influence of fibre orientation on the fibre reinforcement mechanisms is potentially well captured. Therefore, this type of test is suitable for FRC slabs and shells. For being easier of handling, round panels of smaller dimensions $\left(d_{R P}=600 \mathrm{~mm}, h_{R P}=60 \mathrm{~mm}, S_{R P}=275 \mathrm{~mm}\right)$ have been also proposed. From 
round RPT it is obtained the force versus central deflection $\left(F-u_{v}\right)$, as well as the energy versus deflection $\left(U-u_{v}\right)$, where $U$ is the area behind the $F-u_{v}$.

As outlined in Amin et al. (2017), friction through the supports of the ASTM test arrangement, and assumed locations of the fracture lines compared to reality, can considerably enhance the test's predicted strength, thus hindering its capability as design tool without empirical adjustment. This can be readily rectified by adjusting the testing arrangements to remove the friction; as demonstrated by Frazão et al. (2018) with inclusion of spherical supports and Teflon layers.

\subsection{Inverse analysis}

The results from the 3PNBT are currently used to derive, by inverse analysis (IA), the Mode I fracture parameters of FRC, namely the stress at crack initiation, the Mode I fracture energy and the shape of the stress-crack width. The most common IA strategy is based on FEM, with the typical mesh, load and support conditions as represented in Fig. 1. For modelling the fracture propagation, 2D line interface finite elements (IFE), of four or six nodes, are located on the specimen's symmetry axis. In the remaining parts of the specimen four- or eight-node serendipity plane-stress finite elements (SPSFE) are generally used (SenaCruz et al. 2004). Instead of using IFE for modelling the fracture initiation and propagation, the column of material above the notch can be simulated by SPSFE with a smeared crack model by adopting a Gauss-Legendre integration scheme of $1 \times 2$ IP in order to force the propagation of the crack along the specimen symmetry axis, over the aligned integration points (Pereira et al. 2008).

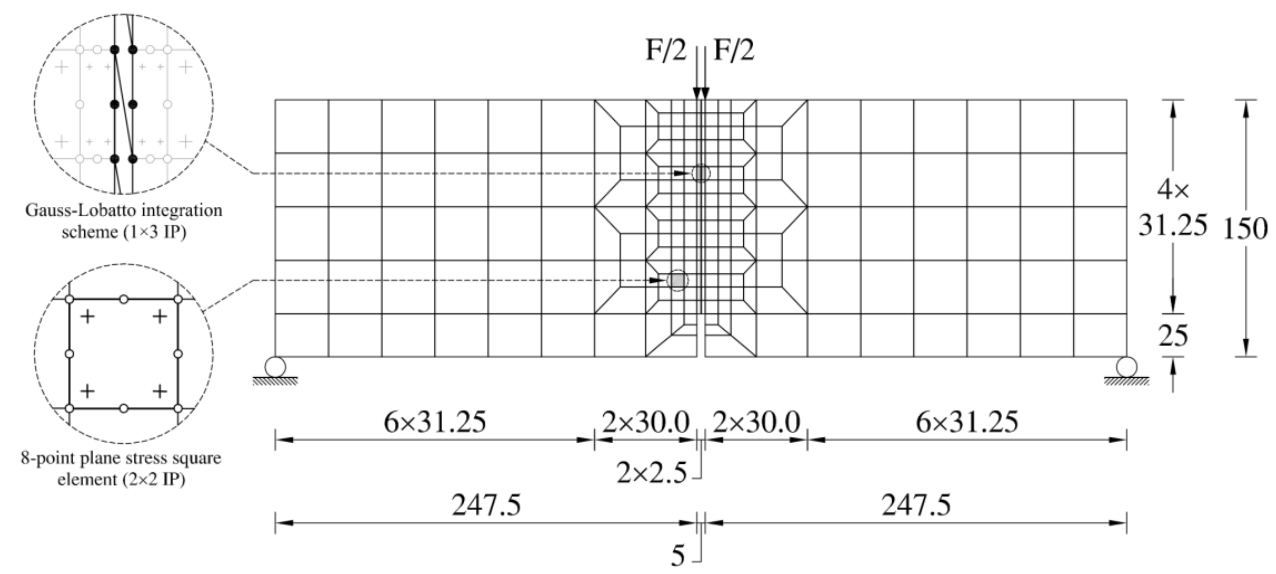

Figure 1 - Inverse analysis approach by simulating 3PNBT based on FEM

By adopting these IA strategies a tendency for overestimation of the post-cracking tensile capacity is reported by several authors (Salehian and Barros 2017, Lameiras et al. 2015, Amin et al. 2015). In the IA it is assumed that the fracture propagation occurs along the notched plane, while in real tests the cracks are tortuous (higher fracture surface), and even micro- and meso-cracks generally form during the propagation of the macro-crack. As a consequence, in assuming that the total energy dissipated in real specimens can be reduced to the energy dissipated in the propagation of a smooth crack surface coinciding with the notched plane, overestimation of the post-crack tensile capacity of the FRC is obtained.

Improved versions of the IA are being proposed by several researchers (Oliveira e Souza and Gettu 2006, Amin et al. 2015, Foster et al. 2017). In the strategy proposed by Foster et al. 
(2017), a $\sigma-w$ relationship is derived, dependent of the $f_{R j}$, but capable of reproducing the $\sigma$ $w$ response in direct tensile tests:

$$
\begin{gathered}
\sigma(w)=k_{G} \min \left(0.4 f_{R 2}+1.2\left(f_{R 4}-f_{R 2}\right) \xi(w), f_{c t k, \min }\right) \\
\xi(w)=\alpha w-0.25
\end{gathered}
$$

where for the prism bending test configuration of EN 14651 and RILEM TC 162-TDF $\alpha=5 / 12$, for the configuration of ASTM C1609 $\alpha=1 / 3$ and for the Italian Guideline $\alpha=$ 43/84, $f_{c t k, \text { min }}$ is the minimum characteristic tensile strength of the matrix (and may be taken

as $\left.f_{c t k, \text { min }}=0.7\left(0.3 f_{c k}^{2 / 3}\right)\right)$ and $k_{G}$ is a factor that takes into account fibre alignment due to casting bias and wall influences that occur in the prism bending test and equals 0.7 for the ASTM 1609 test and 0.6 for the EN 14651, RILEM TC 162-TDF and UNI 11039 tests.

For slab and shell type FRC structures, the $\sigma-w$ relationship can also be derived by using the results $\left(F-u_{v}\right)$ of round and square panel tests described in section 2.2.5. By coupling a moment-rotation model described elsewhere (Barros et al. 2015), with an approach for predicting the $F-u_{v}$ registered in these type of tests that takes into consideration the kinematic conditions of the parts of the panels rotating in turn of the formed cracks, Salehian et al. (2014) developed a strategy for deriving, by inverse analysis, the $\sigma-w$ relationship that characterizes the post-cracking tensile capacity of the panel's FRC.

\section{Approaches for modelling the shear capacity of RC beams}

By performing push-off tests (Figure 2), Lee and Foster (2006a,b) demonstrated that the orientation of fibres crossing the faces of a crack has a decisive influence on the fibre pull-out constitutive law, mainly when shear sliding is the main relative movement of the crack's faces. This influence is represented schematically in Figure 3, showing that fibres at more obtuse angle are first activated and fibres at more acute angles are the last to be activated. This evidenced experimentally through gamma-ray imaging (Figure 4).

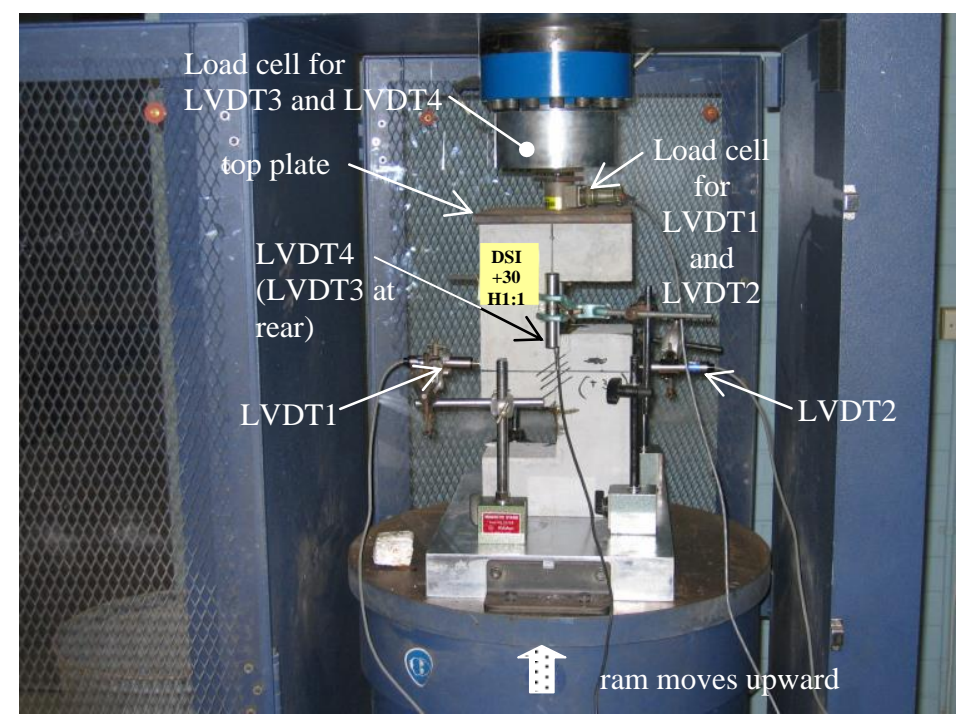

Figure 2 - Push-off tests (Lee and Foster 2006a,b) 

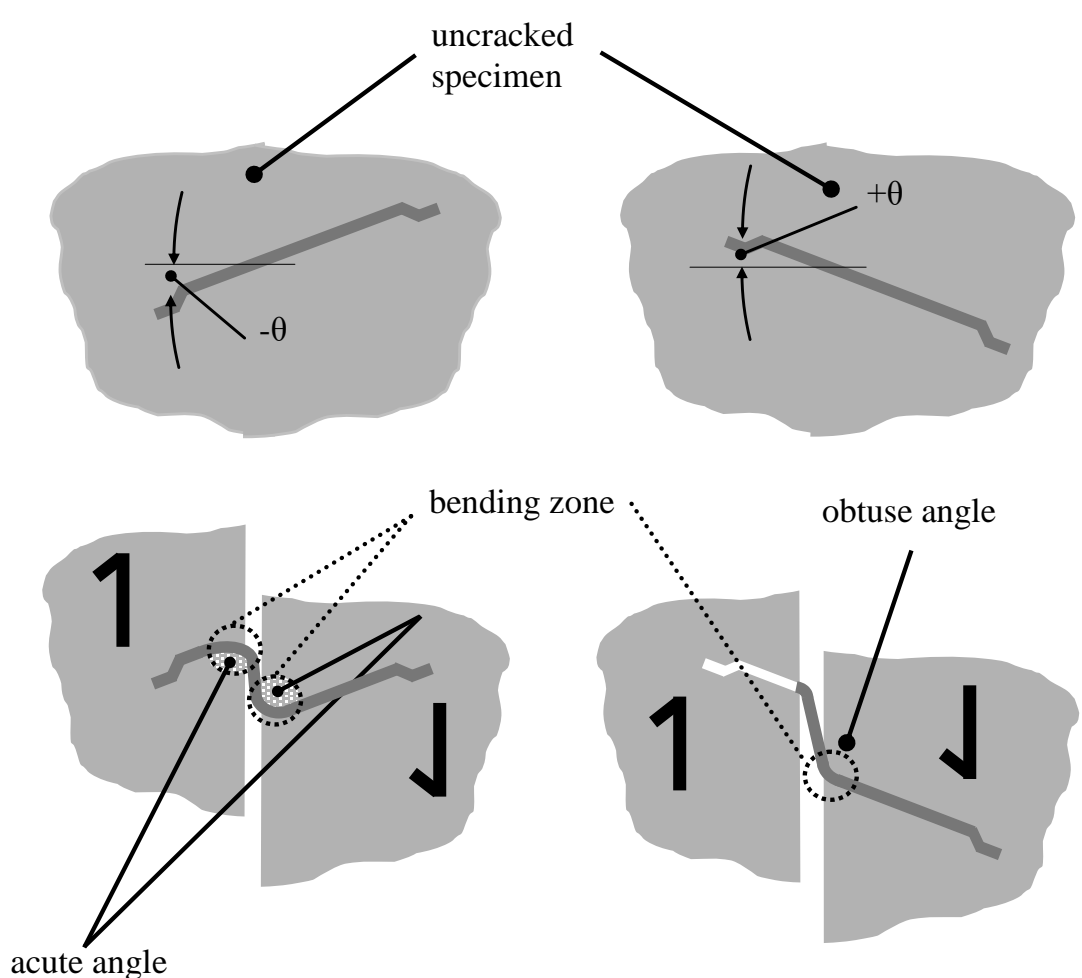

Figure 3 - Schematic representation of fibre engagement (Lee and Foster 2006a)
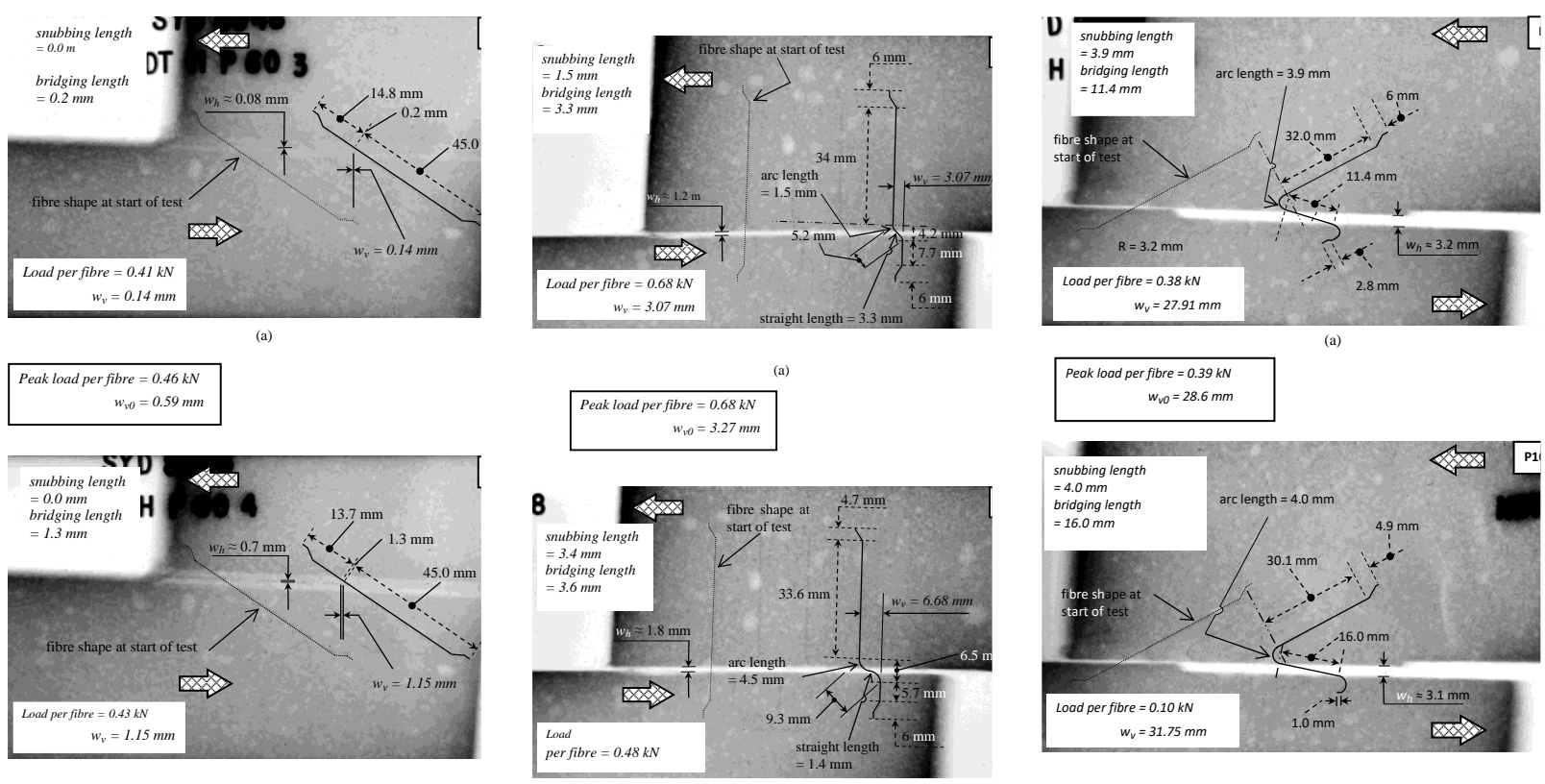

(a)

(b)

(c)

Figure 4 - Gamma-ray imaging showing the influence of the orientation of a fibre on its engagement. Fibre oriented: (a) at obtuse angle; (b) orthogonally to the separation plane; and (c) at an acute angle (Lee and Foster 2007).

From experimental tests, and supported by gamma-ray and X-ray imaging, Htut (2010) proposed that the crack opening displacement at the point where a fibre becomes engaged (i.e. carries significant force) is: 


$$
\begin{gathered}
w_{e}=\frac{1}{3.5} d_{f} \tan ^{3}\left(\frac{\gamma}{\gamma^{\max }} \frac{\pi}{2}\right) \\
\gamma=|\theta-\phi| \text { for } 0 \leq \gamma \leq \pi \\
\gamma^{\max }=|\phi|+\pi / 2 \text { for } \pi / 2 \leq \gamma^{\max } \leq \pi
\end{gathered}
$$

where $d_{f}$ if the fibre diameter, $\gamma$ is the angle between fibre orientation and the loading direction, and $\phi$ is the orientation of loading towards the normal to the crack (Figure 5). Before this displacement is attained, the fibre is ineffective and can be excluded from the analysis.

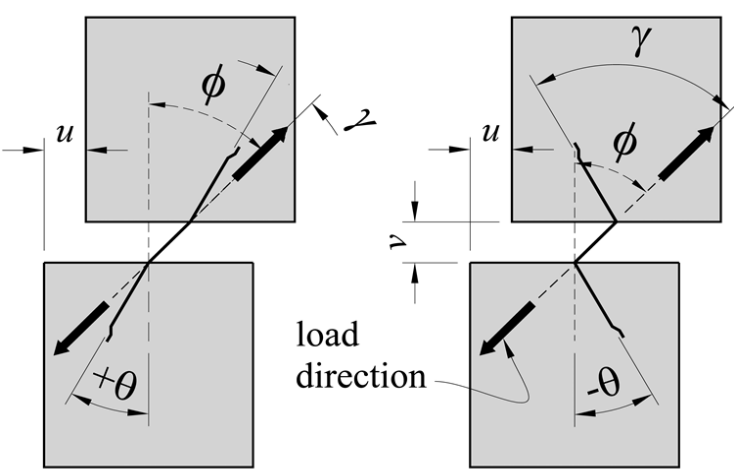

Figure 5 - Fibre orientation and loading direction in fibre engagement concept (Ng et al. 2014).

By integrating and coupling in the same approach: i) a fibre orientation profile for determining the number of fibres crossing the shear crack in discrete intervals of fibre orientation (following the approach proposed by Oliveira, 2010); ii) the fibre pull-out constitutive law determined according to the unified variable engagement model (UVEM); iii) and the modified compression field theory (MCFT) for the evaluation of the crack width at the shear failure stage $\left(w_{u}\right)$ (Bentz et al. 2006), Barros and Foster (2018) proposed an Integrated Shear Model (ISM) for predicting the shear capacity of reinforced concrete SFRC beams (R/SFRC). According to the UVEM, the fibre pull-out constitutive law at crack displacement corresponding to shear failure stage $\left(w=w_{u}\right)$ is obtained from (the subscripts $u$ and $i$ indicate the evaluation is performed at shear failure stage and for the fibres of the $i^{\text {th }}$ interval in the fibre orientation profile):

$$
P_{\bar{\varphi}_{i}}^{F P C L}\left(w_{u}\right)=k_{u, i} \pi d_{f} \tau_{b u, i} L_{b f, o}
$$

where

$$
k_{u, i}=\left\{\begin{array}{cc}
0 & \ldots \text { for }\left\{\begin{array}{c}
w_{u}<w_{e, i} \\
w_{u} \geq L_{b f, o} \\
L_{b f, o}-w_{u} \geq L_{c r u, i}
\end{array}\right. \\
\frac{2\left(L_{b f, o}-w_{u}\right)}{l_{f}} & \ldots \text { for } w_{e, i} \leq w_{u}<L_{b f, o}
\end{array}\right.
$$


In this equation $l_{f}$ is the fibre length, $L_{b f, o}$ is the average bonded length of fibres crossing the failure plane on the short embedment side, considered equal to $l_{f} / 4$ according to Wang (1989), and the critical fibre embedment length, above which fibre fails in tensile rupture is:

$$
\begin{gathered}
L_{c r u, i}=\frac{d_{f}}{2} \frac{\bar{\sigma}_{f u}}{\tau_{b u, i}} \\
\bar{\sigma}_{f u}=\sigma_{f u} \frac{\pi}{2 \gamma_{u}^{\max }}
\end{gathered}
$$

where $\bar{\sigma}_{f u}$ is the fibre's effective tensile strength and $\sigma_{f u}$ is its uniaxial tensile strength. The average fibre bond strength is given by:

$$
\tau_{b u, i}=k_{b} \sqrt{f_{c m}}+f\left[1-\cos \left(\frac{\gamma_{u, i}}{2}\right)\right]
$$

where $f=4.5 \mathrm{MPa}$ is the maximum frictional resistance of the fibre due to the snubbing effect, and $k_{b}$ is a bond coefficient dependent on type of steel fibre, with values available elsewhere (Ng. et al. 2012).

Testing the ISM using a database of 122 reinforced SFRC beams, a predictive performance better than the MC2010 approaches was obtained (Figure 6). In all analyses unit values were used for the safety factors, and average values were used for the material properties.

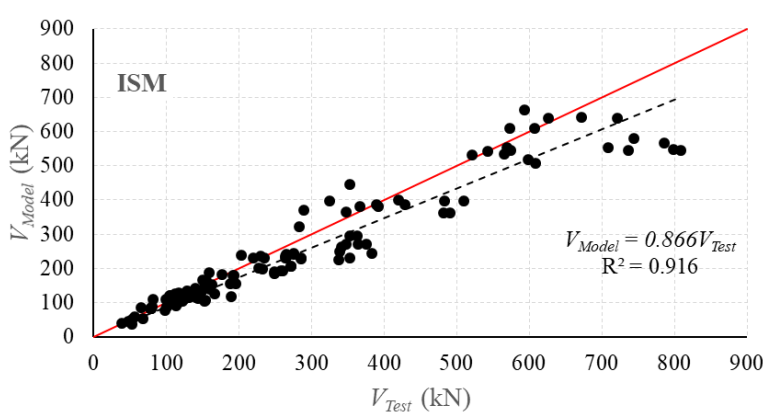

(a)

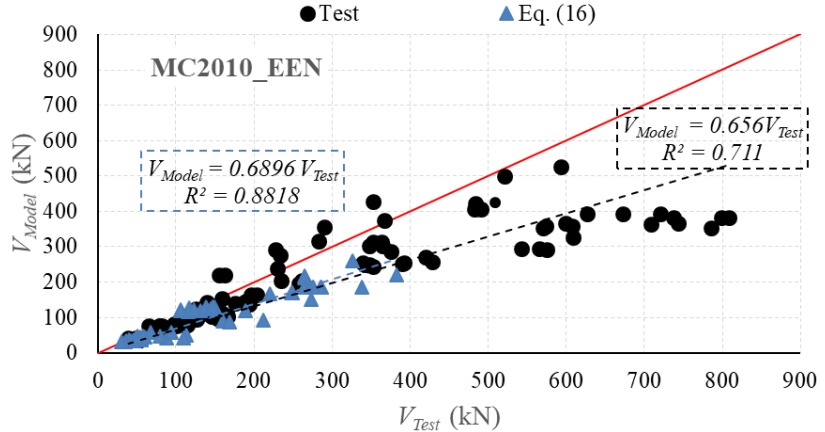

(b)

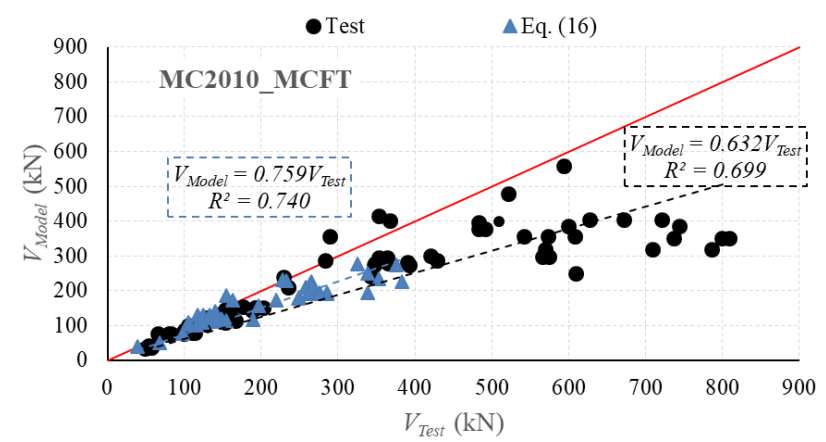

(c)

Figure 6 - Test to model comparisons for shear strength: (a) ISM; (b) MC2010_EEN; (c) MC2010_MCFT. 
The MC2010_EEN model is based on:

$$
V_{R d, F}=\left\{\frac{0.18}{\gamma_{c}} k\left[100 \rho_{e q}\left(1+7.5 \frac{f_{F t u k}}{f_{c t k}}\right) f_{c k}\right]^{1 / 3}+0.15 \sigma_{c p}\right\} b_{w} d_{e q}
$$

The MC2010_MCFT approach represents the MC2010 model based on the MCFT:

$$
V_{R d, F}=\frac{1}{\gamma_{F}}\left(k_{v} \sqrt{f_{c k}}+k_{f} \sigma_{k}\left(w_{u}\right) \cot \alpha\right) z b_{w} \quad \text { with } \sqrt{f_{c k}} \leq 8 M P a
$$

where $\sigma_{k}\left(w_{u}\right)$ is the contribution of the fibre reinforcement to the shear resistance of a reinforced FRC beam, evaluated from Eq. (6), being $w_{u}$ obtained from the MCFT. The details of these two MC2010 formulations are available elsewhere (MC2010, 2013). In the data base, when $f_{R i}$ values were not available for use in Eqs. (4) and (6), they were estimated using the relationship proposed by Moraes-Neto et al. (2013):

$$
f_{R i}=k_{1}\left(V_{f} l_{f} / d_{f}\right)^{k_{2}} \quad \ldots i=1,2,3,4
$$

where $k_{1}=10.5,9.2,8.0 .7 .0$ and $k_{2}=0.80,0.75,0.70,0.65$ for $f_{R 1}, f_{R 2}, f_{R 3}$ and $f_{R 4}$, respectively (the values for $f_{R 2}$ are interpolated from those for $f_{R 1}$ and $f_{R 3}$ ).

The one-way shear models are evaluated and their performance compared. The average and test-to-model prediction ratio $(\lambda)$ and coefficient of variation $(\mathrm{CoV})$ for the ISM approach was 1.12 and 16.6\%, respectively, whereas for the MC2010_EEN and MC2010_MCFT models the averages and CoVs were 1.32 and $23.4 \%$ and 1.32 and $24.2 \%$, respectively.

\section{Concluding remarks}

This paper reports on the different tests used for determining Mode I fracture properties of FRC, and in their application to design models for the determination of shear strength of beams. Shear in reinforced concrete beams, however, involves both sliding and opening displacements and consideration of Mode I fracture alone does not allow for all relevant contributions to behaviour in shear to be considered. A new model for shear is outlined, the integrated shear model (ISM), that has its basis in experimental observations on Model II fracture, including observations from gamma- and X-ray imaging that allow for fibre behaviour during pull-out to be fully observed and considered. The results show that the analytical model performs well when compared with the test data and better than existing approaches.

\section{Acknowledgements}

The authors wish to acknowledge the grant SFRH/BSAB/114302/2016 provided by FCT and the Australian Research Council grant DP150104107, as well as the support provided by the UNSW for the research activities carried out under the status of Visiting Professorial Fellow for the first author. The support of the FCT through the project PTDC/ECMEST/2635/2014 is also acknowledged. 


\section{References}

Abrishambaf, A.; Cunha, V.; Barros, J.A.O., "The influence of fibre orientation on the post-cracking tensile behaviour of steel fibre reinforced self-compacting concrete", Fracture and Structural Integrity Journal, Volume 31, 1, 38-53, January 2016.

Abrishambaf, A.; Barros, J.A.O.; Cunha, V.M.C.F, "Relation between fibre distribution and post-cracking behaviour in steel fibre reinforced self-compacting concrete panels", Cement \& Concrete Research, 51, 57-66, 2013.

Alves, N.; Barros, J.A.O.; Nunes, Â; Lourenço, L.A.P., "Steel fibre reinforced self-compacting concrete for grid foundations of single-family houses", $8^{\text {th }}$ RILEM International Symposium on Fibre Reinforced Concrete: challenges and opportunities, Eds: Joaquim Barros et al., 12pp., 19-21 September 2012.

Amin, A.; Foster, S.J.; Muttoni, A., "Derivation of the $\sigma$-w relationship for SFRC from prism bending tests", Structural Concrete, 16(1), 93-105, 2015.

Amin, A., Foster, S.J., Gilbert, R.I. and Kaufmann, W., "Material Characterisation of Macro Synthetic Fibre Reinforced Concrete", Cement and Concrete Composites, Vol 84, 2017, pp. 124-133

ASTM C1550-05, Standard Test method for Flexural Toughness of Fiber Reinforced Concrete (Using Centrally Loaded Round Panel). West Conshohocken, PA, USA: ASTM International; 2005.

ASTM 1609/C1609-12, "Standard test method for flexural performance of fiber-reinforced concrete (using beam with third-point loading)", ASTM, 9 pages, 2012

Barros, J.A.O.; Foster, S., "An integrated approach for predicting the shear capacity of fibre reinforced concrete beams", in appreciation for eventual publication in an ISI Journal, January 2018.

Barros, J.A.O.; Moraes-Neto, B.N.; Melo, G.S.S.A.; Frazão, C.M.V., "Assessment of the effectiveness of steel fibre reinforcement for the punching resistance of flat slabs by experimental research and design approach", Composites Part B Journal, 78, 8-25, September 2015.

Barros, J.A.O.; Taheri, M.; Salehian, H., "A model to simulate the moment-rotation and crack width of FRC members reinforced with longitudinal bars", Engineering Structures, 100, 43-56, October 2015.

Bentz EC, Vecchio FJ, Collins MP. Simplified modified compression field theory for calculating shear strength of reinforced concrete elements. ACI Structural Journal, 103:614-624, 2006.

Carnovale, D.; Vecchio, F.J., "Effect of fiber material and loading history on shear behavior of fiberreinforced concrete", ACI Structural Journal, 111(5), 1235-1244, 2014.

Deluce, J.R.; Vecchio, F.J., "Cracking behaviour of steel fibre reinforced concrete members containing conventional reinforcement”, ACI Structural Journal, 110(3), 481-490, 2013.

di Prisco M., Ferrara L., Lamperti M.L., "Double edge wedge splitting (DEWS): an indirect tension test to identify post-cracking behaviour of fibre reinforced cementitious composites", Materials and Structures 46 (11):1893-1918, 2013.

EN 14651. Test method for metallic fibre concrete-measuring the flexural tensile strength (limit of proportionality (LOP), residual). European Committee for Standardization; 2007: p. 17.

Foster, S.J.; Agarwal, A; Amin, A., "Design of SFRC Beams for Shear using Inverse Analysis for Determination of Residual Tensile Strength”, Structural Concrete [DOI: 10.1002/suco.201700100], 2017.

Frazão, C.; Barros, J.A.O.; Bogas, J.A.; Pilakoutas, K., “An experimental investigation on the post-cracking behaviour of Recycled Steel Fibre Reinforced Concrete", FRC2018: Fibre Reinforced Concrete: from Design to Structural Applications Joint ACI-fib-RILEM International Workshop, Brescia, Italy, 2018.

Htut TNS. Fracture processes in steel fibre reinforced concrete. PhD dissertation. School of Civil and Environmental Engineering, The University of New South Wales, UNSW Sydney, Australia; 2010.

Lameiras, R.M.; Barros, J.A.O., Azenha, M.A.D., "Influence of casting condition on the anisotropy of the fracture properties of Steel Fibre Reinforced Self-Compacting Concrete (SFRSCC)", Cement and Concrete Composites, 59, 60-76, May 2015.

Lee, G.G.; Foster, S.J., "Behaviour of steel fibre reinforced mortar in shear III: variable engagement model II”, UNICV Report R-448, UNSW, Sydney, Australia, 2007.

Lee GG, Foster SJ. Behaviour of steel fibre reinforced mortar in shear II: Gamma ray imaging. UNICIV Report No. R-445. The University of New South Wales, UNSW Sydney, Australia; 2006b. 
Lee GG, Foster SJ. Behaviour of steel fibre reinforced mortar in shear I: Direct shear testing. UNICIV Report No. R-444. The University of New South Wales, UNSW Sydney, Australia; 2006a.

Model Code 2010. fib Model Code for Concrete Structures 2010. International Federation for Structural Concrete (fib). Ernst \& Sohn, Berlin, Germany; 2013.

Ng, T.S.; Foster, S.J.; Htut, M.L.; Htut, T.N.S., "Mixed Mode Fracture Behaviour of Steel Fibre Reinforced Concrete, Materials and Structures", Vol. 47, Issue 1-2, pp. 67-76, 2014.

Oliveira FL. Design-oriented constitutive model for steel fiber reinforced concrete. $\mathrm{PhD}$ dissertation. Department of Project and Construction Engineering, Polytechnic University of Catalonia, Catalonia, Spain; 2010.

Pereira, E.N.B.; Fischer, G.; Barros, J.A.O., "Direct assessment of tensile stress-crack opening behavior of Strain Hardening Cementitious Composites (SHCC)", Cement and concrete Research, 42, 834-846, 2012.

Pereira, E.B.; Barros, J.A.O., Camões, A.F.F.L., "Steel fiber reinforced self-compacting concrete experimental research and numerical simulation", ASCE Structural Engineering Journal, 134(8), 1310-1321, August 2008.

Salehian, H.; Barros, J.A.O., "Prediction of the load carrying capacity of elevated steel fibre reinforced concrete slabs", Composite Structures Journal, 170, 169-191, 2017.

Salehian, H.; Barros, J.A.O.; Taheri, M., "Evaluation of the Influence of Post-Cracking Response of Steel Fibre Reinforced Concrete (SFRC) on Load Carrying Capacity of SFRC Panels", Construction and Building Materials Journal, 73, 289-304, December 2014.

Sena-Cruz, J.M.; Barros, J.A.O.; Ribeiro, A.F.; Azevedo, A.F.M.; Camões, A.F.F.L., "Stress-crack opening relationship of enhanced performance concrete", 9th Portuguese Conference on Fracture, ESTSetúbal, Portugal, p. 395-403, 18-20 February 2004.

Susetyo, J., "Fibre reinforcement for shrinkage crack control in prestressed, precast segmental bridges", $\mathrm{PhD}$ thesis, University of Toronto, Canada, 2009.

UNI 11039. Steel Fiber Reinforced Concrete-Part I: Definitions, Classification Specification and Conformity - Part II: Test Method for Measuring First Crack Strength and Ductility Indexes. Italian Board for Standardization: Rome, Italy; 2003.

Voo, Y.L.; Foster, S., "Reactive powder concrete analysis and design of RPC girders", Lambert Academic Publishing, 2009.

Wang, Y., "Mechanics of fiber reinforced cementitious composites", Ph.D. Thesis, Massachusetts Institute of Technology, May 1989. 